\begin{abstract}
"Mircea cel Batran" Naval Academy Scientific Bulletin, Volume XX - 2017 - Issue 1
The journal is indexed in: PROQUEST / DOAJ / Crossref / EBSCOhost / INDEX COPERNICUS / DRJI / OAJI I

JOURNAL INDEX I I2OR / SCIENCE LIBRARY INDEX / Google Scholar / Academic Keys/ ROAD Open Access I Academic Resources / Scientific Indexing Services / SCIPIO / JIFACTOR
\end{abstract}

\title{
THE EXPERT SYSTEM DEVELOPMENT TECHNOLOGIES IN CLOUD
}

\author{
Violeta N. OPRIS ${ }^{1}$ \\ Madalina E. OPR̉IȘ \\ ${ }^{1}$ Ph.D. Student The Military Technical Academy, Faculty of Military Electronic and Information Systems, \\ Bucharest, violeta.opris@yahoo.ro \\ ${ }^{2}$ Ph.D., Teaching Assistant, The Bucharest University of Economic Studies, Accounting and Audit \\ Departament, Bucharest' madalina.opris@cig.ase.ro
}

\begin{abstract}
The technologies used for an expert system development have an essential role and take the architecture to the next level of innovation. These innovations provide essential assistance to save energy, resources and also to secure the required infrastructure. The paper concentrates on the innovative technologies used for building an expert system. An expert system also comprises an Interface within users interact and an Interface Engine that performs knowledge reasoning. The proposed architecture interconnects multiple programming languages, hardware and software components to build the system.

Keywords: Technology, Cloud computing, Expert systems, Security, Sustainability, Innovation, Efficient costs
\end{abstract}

\section{Introduction}

The IT leverages value creation and becomes a strategic asset for any organization, redefining economic and social approaches [22]. Brought together, traditional conception of human development and human existence will root innovation need, which IT represents.

The continuous globalization process is a challenge for managing economic and environmental issues and multidimensional performance [18]. As the attention and market pressure are focused on reducing the impact of businesses on social and natural environment, organizations have tried hard to monitor and optimize their impact within society.

Sustainable performance should create a better life for humans. Living and nonliving natural systems ensure a company's survival if it shows responsibility for the environment [17]. Increasing social quality and minimizing the negative effects on the environment lead to renewable energy sources. Minimizing the use of energy and natural resources will provide a healthy environment for human beings, which is a pillar for life development at macro level.

In order to mitigate the climate changes, consumers have become more preoccupied with the quality of life and organizations responded.

They reduced carbon emissions and energy use and developed innovative IT technologies.

According to Williams [22], in an unprecedented era of sustainability, adoption of Cloud Computing may seem to take time, but its favorable economic impact and human development speed the process. Innovation improves life quality, reduces long-term costs and aligns economic positive impact with social and environmental issues. Cloud can simplify and restructure technology use in businesses and compress unnecessary costs in the context of limited resources.
Because economic problems are real barriers that block access to IT resources, Cloud Computing enhances performance when creating hybrid strategies with cost saving potential and improves profitability and reputation. It decreases costs by reducing energy use, it reduces transaction risks and promotes organizational collaboration [18].

In recent years, more business including many retailers and government agencies, are testing different forms of biometrics.

In this paper, we have used an expert system in cloud infrastructure. The paper proposed two components, hardware and software for expert system and multiple technologies for development.

As any management decision has deep economic reasons, migrating to Cloud is uncertain. Taking advantage of technology may lead to higher consumption of it, which means higher costs [22]. However, the ability to support and develop businesses over time shows great potential for Cloud to become an organizational strategy itself. Web-based expert system development has been considered a complex, multidisciplinary and knowledge driven process [5]. The development technologies and the associated applications are currently of unprecedented interest and importance to a variety of communities in cyberspace.

The trend of methodology development is also diversified due to author's research interests and abilities in the methodology and problem domain. This shows that the development of expert system methodologies is directed toward expertise orientation [5].

The paper is divided in five sections. In the first section, we present an overview of expert systems, the second section contains a review of the most important existing solutions, in the third section we present our proposed architecture, the 


\section{"Mircea cel Batran" Naval Academy Scientific Bulletin, Volume XX - 2017 - Issue 1 The journal is indexed in: PROQUEST / DOAJ / Crossref / EBSCOhost / INDEX COPERNICUS / DRJI / OAJI I JOURNAL INDEX I I2OR / SCIENCE LIBRARY INDEX / Google Scholar / Academic Keys/ ROAD Open Access I Academic Resources / Scientific Indexing Services / SCIPIO / JIFACTOR}

fourth part describes the role of the security in cloud, in the last section we present the conclusion of our work.

\section{Literature review. Research methods for expert systems}

Migrating a classic expert system (ES) infrastructure to the cloud is a complex process that requires careful planning and deliberation.

This process can have unexpected costs, interoperability, security gaps and can create significant obstacles. But cloud computing has essential benefits and today most of the enterprises use it.

The expert systems are computer applications developed to solve complex problems at the level of extraordinary human intelligence and expertise [31].The most important characteristics of an expert system refer to the ability to process a large amount of knowledge and to simulate human reasoning. The general elements of expert systems are: knowledge based, decision engine and user interface.

According to different criteria, expert systems can be classified as: systems that think like humans, systems that think rationally, systems that act like humans and systems that act rationally.

Expert systems involve complex developmental stages. These steps are important to satisfy the initial system: initial problem, knowledge acquisition, design and implementation, testing, user manual and system documentation, maintenance [31].

The system has essential characteristic like high performance, understandable, reliable, and highly responsive. It also has capabilities as instructing and assisting humans in decision making, diagnosing, and substituting human decision makers [3].

The Edward Feigenbaum was called "the father of expert systems." According to Feigenbaum the key insight of early expert systems was an intelligent system. [33].The first programming environment in the US was LISP. In France, research focused more on systems developed in Prolog.

The option of virtualization means that companies do not need to own data centers anymore, they can store, process and analyze information using Cloud Computing. This could decrease energy use on large scale, which balances economic and environmental performance. When using multiple IT hardware, energy efficiency shows low levels, but Cloud comes with the individual possibility of sharing information on multiple platforms, from different locations, within and between users [18]. Within this section, we emphasize the current solution development technologies generated by the expert systems architecture from the last years.

Liao makes a survey of expert system applications and methodologies during 19952004 [10]. The methodologies were divided in rule-based systems, knowledge-based systems, neural networks, fuzzy expert systems, objectoriented methodology, case-based reasoning, modeling, system architecture, intelligent agents, ontology, and database methodology.

The concept of an expert system development is under the attention of the research community. The development of a web-based expert system is a multidisciplinary and complex task. Above all, an important factor is the lack of research and of general methodology for developing web-based expert systems.

Nowadays we assist a considerable evolution of the expert system. The existing literature on webbased expert system is mainly focused on the development of expert system component and pays little attention to the web component of the application [8.].

An important aspect of the development process is that there are many limiting factors that influence the complexity of the software under development such as process requirements, adopted methodology, software engineer expertise, and user requirements.

Dokas and Alapetite have presented a development meta-model for web-based expert systems with the combined experience of web engineering and expert system [6.].

Recently, the most important web-based technologies are spring MVC security, java, JavaScript, JDBC, Oracle DB, html, bootstrap, angular. An essential part of developing successful web applications is optimizing the files that comprise them. Technologies trend enhance the capabilities of an expert system [13]. ModelView-Controller (MVC) architecture and web application optimize the strategies in order to achieve high usability.

Numerous studies related to innovation start by using the sentence "innovation is crucial to survival"[5]. The technological innovation process starts with technical discovery of new things or new ways of doing things.

Franttiand Majanen [17] explore an expert system for real-time traffic management in wireless local area networks, the delay-based congestion and flow control and the offloading of real-time traffic from wireless local area networks (WLANs) to mobile cellular networks (MCNs). The control system developed is based on an embedded hierarchical expert system [7].

The experts have found many applications in various domains such as medical, military, education [16]. Barreto and Azevedo use neural 
networks as associative memories to build a connectionist expert system for aiding medical diagnosis [3].

\section{Cloud computing overview}

According to NIST, Cloud computing represents a model for enabling ubiquitous, convenient, ondemand network access to a shared pool of configurable computing resources [27].

The SANS institute research claims that Cloud computing reduces IT expenditures, improves scalability and reduces administrationcosts. Delivering IT services via Cloud portends to be a time and money saver, which increases efficiencies [20].

The economics of Cloud Computing lies in the fact that significant volumes of resources come together within a data center, which ensures sharing and exchanging information between different users.

Cloud's business value increases if data is processed and financial or non-financial measures are reported to users, which is yet a high demand [22].Public Clouds represents a multi-tenant service similar to the electricity utility model, without knowing where or how the services are created. Private clouds offer similar capabilities to public clouds, but they run on dedicated IT only. Hybrid clouds combine private and public infrastructure services to offer security and scalability. An issue that could delay Cloud adoption is security [22]. Cloud security is a sensitive issue for many organizations. The level of uncertainty persists as environmental circumstances change quickly and collaboration switches actors worldwide.

Cloud Computing creates long-term relationships within different entities that have common strategies and work together to share information [11].

The virtual space that provides external platforms for collaboration offers security and improves the customer's' perception on data security [18].

It also improves economic and environmental performance because economic resources savings can now be used for social and environmental investments when using Cloud.

Currently, we assist a considerable evolution of the cloud computing architecture. In Armbruts et al. perspective, cloud computing refers to the applications delivered as services over the Internet [1]. The concept was introduced in 1960s by John McCarthy and it has been widely recognized as the next generation computing infrastructure.

According to the Gartner Report 2016, sophisticated hacking attacks are continuously increasing in the cyber space. Before implementing this method of computing, it is important to consider the security of the cloud.

Because security in cloud computing represents an important issue, studied cloud security for data integrity, confidentiality, and authentication through a model that uses hyper crypto-encryption [21].Today, cloud computing is an attractive and cost-saving service for buyers as it provides accessibility and reliability for users and scalable sales for providers [12].

However, cloud computing achieves higher throughput and deals with virtualization, scalability, interoperability, quality of services and the delivery models of the cloud.

Apparently, cloud computing has gradually evolved and IT industry has already started to accept virtualization [9]. Among the benefits for expert system architecture, virtualization centralizes and integrates IT resources.

Recent researches and studies show challenging and beneficial aspects of virtualization regarding information security. The concept of virtualization originated in 1960. Many companies have started to find ways to decrease IT costs and overcome economic recession [2].

\section{The proposed software and hardware architecture of the expert system in Cloud Computing}

In this article we present a novel architecture model that offers the clients a high level of security and innovation for an expert system infrastructure. It is divided between software and hardware.

The proposed architecture is in the cloud for enhanced innovation, higher security, privacy, higher level of control, efficiency of costs and energy, improved reliability and cloud bursting.

Starting from on-demand scalability, it is very important that the expert system infrastructure be based on the most secured and essential technologies. The expert systems infrastructure will be implemented in cloud to reduce the number of servers, to centralize and integrate IT resources. It also conforms to the pervasive trend toward global green energy. This paper brings contributions and innovation for classical expert systems architecture by migrating the infrastructure in a cloud environment.

\section{Software architecture of the expert system}

The software architecture model was designed for the expert system. The software architecture is divided into two components: front-end and backend. The front-end will be developed using HTML and angularJS. HTML stands for HyperText Markup Language, it was created by Berners-Lee in late 1991. AngularJS is a very powerful 


\section{"Mircea cel Batran" Naval Academy Scientific Bulletin, Volume XX - 2017 - Issue 1 The journal is indexed in: PROQUEST / DOAJ / Crossref / EBSCOhost / INDEX COPERNICUS / DRJI / OAJI I JOURNAL INDEX I I2OR / SCIENCE LIBRARY INDEX / Google Scholar / Academic Keys/ ROAD Open Access I Academic Resources / Scientific Indexing Services / SCIPIO / JIFACTOR}

JavaScript Framework. It is used in Single Page Application (SPA) projects andJavaScript that is a lightweight, interpreted programming language.

It is designed for creating network-centric applications and integrated with Java (Figure 1). The back-end will center around the Java and JDBC technologies. Java is a high-level programming language originally developed by Sun Microsystems. JDBC stands for Java Database Connectivity, which is a standard Java API for database-independent connectivity between the Java programming language and a wide range of databases.

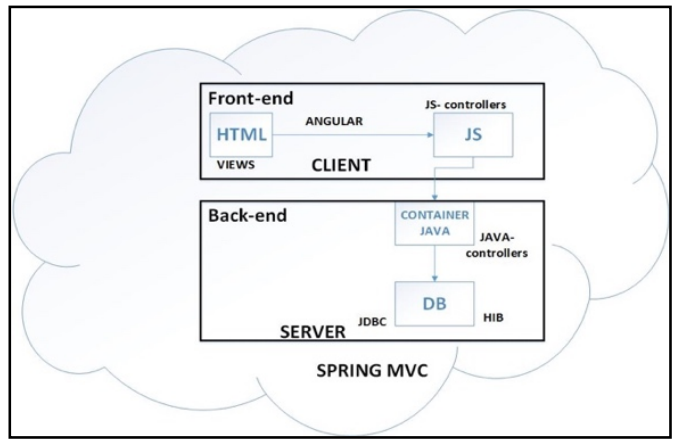

Figure 1. The proposed architecture software model

The Spring Web model-view-controller (MVC) framework is centered around a DispatcherServlet that dispatches requests to handlers with configurable handler mappings, view resolution, locale and theme resolution. The Controller mechanism creates RESTful Web applications, through the@PathVariable annotation and other features [24].

Software engineers implement similar architectural solutions in their projects. The main idea of MVC is to separate the code that deals with UI (view).

\section{Hardware architecture of the expert system}

The proposed architectural hardware model is based on proven technology over time in similar deployments and complies with the conditions recommended by good practices in the field of security and system redundancy.

The hardware infrastructure was implemented in cloud to improve security control and to integrate IT resources.

The expert system architecture in cloud has the following components: back-end, front-end, and the transaction subsystem

Using these technologies, the expert system is not dependent on the existent operating systems on the server that will be installed, thus ensuring a high degree of portability.
The machines will be distributed in stellar architecture, each machine being connected directly.

Regarding the development model that we propose, the expert system refers to three tier architecture.

The three-tier architecture requires that validation rules be stored in a proper environment, so that client applications can use them independently of each other and of existing data.

In this way, the client application provides the interface, the database server provides data and the second-tier handles data validation.

There are two client-server communications, one between client applications and the second tier and the other between the second tier and the server databases.

The mechanism of network layout of the four machines allows increasing the availability meaning that if the hardware/software resident on a machine becomes unavailable, software services running isolated on the machine can be quickly switched to an available one.

In Cloud, the hardware architecture will map as follows:

The Back-end is the core of the application. The component implements processes and requirements. At the transport layer, the proposed architecture protects data flows through direct communication mechanisms described above. All traffic is secured by encryption and authentication. Traffic JDBC between the application server and database server is isolated from traffic internet. The chosen technical solution is Oracle JDBC which enables using encryption and SSL for securing the data stream.

HTTPS traffic between the application server and Web server is performed using secure HTTPS traffic and it is generated only by the web server which will require the necessary information.

In terms of data storage, data security contained in the database is done on several levels: level of connectivity, level of authentication server-level database security by controlling user, operating system level by controlling which users can read data from files that were stored in the database, level of storage component.

Presentation layer is the component that has direct connection with the user. The presentation layer will be provided via a web interface. It consists of the elements of the graphical user interface.

Application layer is the component that includes all application logic. It consists of several components, framed by two levels of filtration. The first level of filtration is the security filter. It will apply to any work that comes from the presentation layer. The second level of filtering will be the log. It will log the data any change, 


\section{"Mircea cel Batran" Naval Academy Scientific Bulletin, Volume XX - 2017 - Issue 1 The journal is indexed in: PROQUEST / DOAJ / Crossref / EBSCOhost / INDEX COPERNICUS / DRJI / OAJI I JOURNAL INDEX I I2OR / SCIENCE LIBRARY INDEX / Google Scholar / Academic Keys/ ROAD Open Access I Academic Resources / Scientific Indexing Services / SCIPIO / JIFACTOR}

because any operation that aims to change the data passes through this filter.

Data layer is the database. It will have two components: database operational and, upon request, database journaling.

The front-end consists of two components: a component that has direct connection with the user and a component dedicated to interfacing with other systems.

The transaction Subsystem ensures the flow of actions taken by an expert system. For each authentication, an authorization code is used to log messages.

\section{The proposed software and hardware architecture of the expert system in Cloud Computing}

There are organizations that focus on cloud security standards. The Cloud Security Alliance (CSA), NIST (National Institute of Standards and Technology), and the Open Cloud Computing Interface $(\mathrm{OCCl})$ are examples of organizations promoting cloud security standards. The Open Data Center Alliance (ODCA), an alliance of customers, recognizes that security is the biggest challenge organizations face as they plan for migration to cloud services.

According to the NIST definition, cloud computing allows cloud service providers and consumers alike to establish an initial set of expectations about management, security, and interoperability, as well as to determine the value derived from cloud technology use [23].

Clearly, the cloud provider security used for the proposed expert system involves technology, products, solutions that span mobility, networks security, web security, messaging security, protection of data or content and storage, identity management, hypervisor and platform security, firewalls, and audit and compliance [23].

Today, there are many definitions and industry descriptions for the trusted term cloud, but at core these definitions all have four foundational pillars: a trusted computing infrastructure, a trusted cloud identity and access management, trusted software and applications, operations and risk management. Trusted computing infrastructure is based on cryptographic and measurement techniques to enforce a selected behavior by authenticating the launch and authorizing processes. The security is an ever-present consideration for applications and data in the cloud.

Nowadays, there are many cloud providers. In Gartner Report 2016 made by Lydia Leong, Gregor Petri, Bob Gill, Mike Dorosh analysts, it is strongly emphasized the vendors profiles. Amazon Web Services (AWS), the subsidiary of Amazon, is the leader of cloud computing vendors. The expert system will be in the cloud. Following the advice of the researchers we are using AWS for cloud infrastructure. It is a cloudfocused service provider and offers Xenvirtualized multitenant and single-tenant compute (Elastic Compute Cloud [EC2]), with multitenant storage, along with extensive additional laaS and PaaS capabilities, including object storage with an integrated CDN (Amazon Simple Storage Service [S3] and Cloud Front), a Docker container service (EC2 Container Service [ECS]), event-driven "serverless computing" (Lambda), and an aPaaSlike developer experience (Elastic Beanstalk).

There are multiple benefits of moving expert system infrastructure to the cloud. It reduces operational costs and the demand on hardware resources, just as virtualization has already done. It allows remotely located employees to access applications and work, it will automatically track and upgrade server software. The most significant benefit of moving to the cloud is reduced management costs.

The cloud computing security infrastructure of the expert system is the highest priority.

There are a lot of benefits of AWS infrastructure security: all data is stored in highly secure AWS data centers, it manages dozens of compliance programs in its infrastructure and reduced costs by using AWS data centers. No matter the size of the business the AWS infrastructure is designed to keep data safe(Figure 3).

The infrastructure of the expert systems has a data center and a network architecture built to meet the requirements of the most securitysensitive organizations. AWS cloud allows expert system to scale and innovate, while maintaining a secure environment (Figure 2).

The proposed architectural model also assumes to build the cloud computing security infrastructure for the expert system.

The expert system from cloud involves also to map the requirements security with technologies used to develop it. In the current environment, the cloud provider ensures the security infrastructure and the expert system offers secure algorithms.

The algorithms used for symmetric and asymmetric encryption are DES (521) and RSA (2048). The Data Encryption Standard is a block cipher, meaning a cryptographic key and algorithm are applied to a block of data simultaneously rather than one bit at a time. RSA represents public-key cryptosystems and is used for secure data transmission. 


\section{"Mircea cel Batran" Naval Academy Scientific Bulletin, Volume XX - 2017 - Issue 1 The journal is indexed in: PROQUEST / DOAJ / Crossref / EBSCOhost / INDEX COPERNICUS / DRJI / OAJI I JOURNAL INDEX / I2OR / SCIENCE LIBRARY INDEX / Google Scholar / Academic Keys/ ROAD Open Access I Academic Resources / Scientific Indexing Services / SCIPIO / JIFACTOR}

\section{Conclusions}

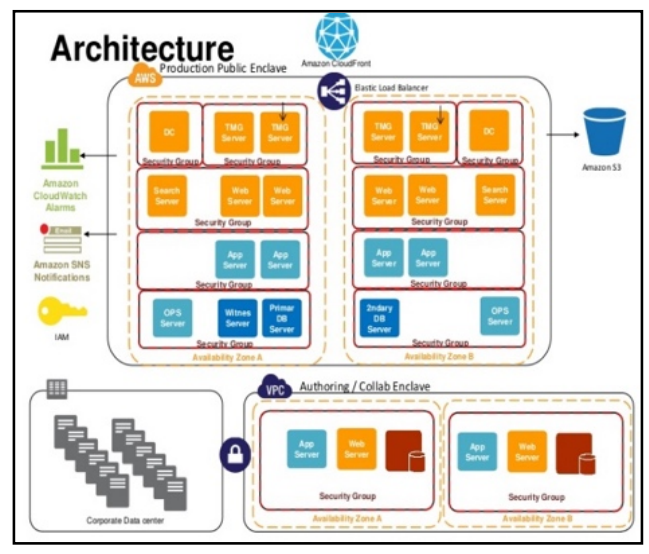

Figure 2. Cloud security at AWS - Global Infrastructure [30]

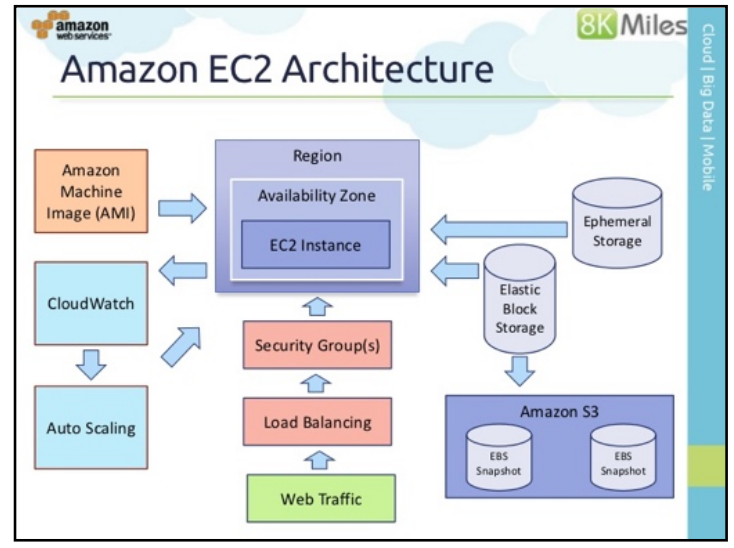

Figure 3. Amazon Elastic Compute Cloud (EC2) [30]

Stakeholders exert pressure on companies. They ask for significant information about the economic, social and environmental dimensions of sustainability. In return, companies provide information on value creation, about actions taken to achieve performance, and the results that stakeholders expect [19].

A company's responsibility crossed the line of financial performance [17], high profits do not reveal strong organizational behavior and positive impact on the environment. Nowadays, sustainability has become a controversial issue for business environment. The challenge of energy conservation leads to sustainable investments and enhance competitiveness, but it needs permanent efforts.

It is difficult for organizations to develop innovative environmental and economic performance tools that could increase stakeholders trust. Anything, but economic measures, is difficult to quantify, but companies have to prove their ability to minimize costs and to improve efficiency. Cloud Computing supports the process because it offers the opportunity to analyze large amount of data within short intervals and it provides platforms to store significant information [18].

The speed of Cloud Computing integrating into innovative businesses and reliable governance models enhances decision making [22]. Along with economic environment development, it leads to new markets rising and seeking for equilibrium. It also highlights the need for a cleaner environment in the context of aggressive global development and addresses vital needs in order to alleviate existential issues.

In this paper we have presented a novel architecture for an expert system provided from cloud. The infrastructure is divided into two components: software and hardware in a virtualized space. We have 


\section{"Mircea cel Batran" Naval Academy Scientific Bulletin, Volume XX - 2017 - Issue 1 The journal is indexed in: PROQUEST / DOAJ / Crossref / EBSCOhost / INDEX COPERNICUS / DRJI / OAJI I JOURNAL INDEX I I2OR / SCIENCE LIBRARY INDEX / Google Scholar / Academic Keys/ ROAD Open Access I Academic Resources / Scientific Indexing Services / SCIPIO / JIFACTOR}

proposed an innovative architecture that is centered around the cloud for enhanced innovation, higher security, privacy, higher level of control, efficiency of costs and energy, improved reliability and cloud bursting.

The first part of the paper presents a descriptive introduction of expert system, cloud computing and, network security from a sustainable perspective. The cloud innovation improves life quality, reduces long-term costs and aligns economic positive impact with social and environmental issues.

In the second part of the paper a review of current development technologies was made. There were described the technologies used for the expert system.

The third part of the article represents the proposed architecture. It is significant the fact that the proposed architecture was implemented in cloud to reduce the number of servers, to centralizes and integrate IT resources. In the fourth part we build the cloud security infrastructure for the expert system. It also conforms to the pervasive trend toward global green energy. In the last section we present the conclusion of our work. The research highlights the influence of the expert development technologies in cloud computing and the information security environment.

The results of the proposed software and hardware architecture of the expert system in cloud show that the implementation of the novel infrastructure offers a high level of innovation proven to be particularly beneficial of information security.

This study reveals that hardware cloud infrastructure form the provider has a significant influence on information security, all data is stored in highly secure AWS data centers. Starting on-demand scalability from cloud, the paper roughly introduces the new structure and components of the expert system.

The most significant contribution of this work is the connection between a classic expert system and a new secure infrastructure in a cloud environment. Considering the benefits of the implementation, this study provides new approaches of investigating the technologies used for development.

Despite the aforementioned findings, the proposed architecture introduces a new concept of using an expert system in a secure cloud, deploying two architectures. As a future research work, we plan on building a strong and secure architecture to provide an expert system.

\section{Bibliography}

[1] Armbrust, M., A. Fox, R. Griffith, A. D. Joseph, R. Katz, A. Konwinski, G. Lee, D. Patterson, A. Rabkin, I. Stoica and M. Zaharia (2009). Above the Clouds: A Berkeley View of Cloud Computing. EECS Department, University of California, Berkeley

[2] Bajanova, I., Samba, A. - Analysis of Cloud Computing Delivery Architecture Models, Workshops of International Conference on Advanced Information Networking and Applications, 2011.

[3] Barreto, J. M., De Azevedo, F. M. (1993). Connectionist expert systems as medical decision aid. Artificial Intelligence in Medicine, 5(6), 515-523

[4] Chang, V., Walters, R.J., Wills, G.B., Organisational sustainability modeling - An emerging service and analytics model

[5] Dereli, T., Altun, K., A novel approach for assessment of candidate technologies with respect to their innovation potentials: Quick innovation intelligence process, Expert Systems with Applications, Department of Industrial Engineering, Gaziantep University, 27310 Gaziantep, Turkey

[6] Dokas, I. M., \& Alapetite, A. (2006). A view on the web engineering nature of web based expert systems. In ICSOFT 2006 - International conference on software and data technologies (pp. 280-283)

[7] Frantti, T., Majanen, M., An expert system for real-time traffic management in wireless local area networks, Expert Systems with Applications 41 (2014) 4996-5008, 2011 Elsevier

[8] Hasan, S.S, Isaac, R.K. An integrated approach of MAS-CommonKADS, Model-View-Controller and web application optimization strategies for web-based expert system development, Expert Systems with Applications 38 (2011) 417-428

[9] Li,S.H., Yen, D.C, Chen, S. C, Chen, P., S., Lu, W., H., Cho, C., C, Effects of virtualization on information security, Elsevir, Computer Standards \& Interface 42 (2015) 1-8

[10] Liao, S.-H. (2005). Expert system methodologies and applications - A decade review from 1995 to 2004. Expert Systems with Applications, 28, 93-103.

[11] Mathew, S., Jose, A., P., Securing Cloud from Attacks based on Intrusion Detection System, International Journal of Advanced Research in Computer and Communication Engineering, Vol1, Issue 10, December 2012.

[12] Niari, E.S., Mahdi, K.E., Zbakh, M., Cloud Computing Architectures Based IDS, 978-1-4673-47662/12/\$31.00 (C2012 IEEE

[13] Rafea, A., El-Azhari, S., Hassan, E. (1995). Integrating multimedia with expert systems for crop production management. In Proceedings of the 2nd international IFAC workshop on artificial intelligence in agriculture, Wageningen, The Netherlands, May 1995 
"Mircea cel Batran" Naval Academy Scientific Bulletin, Volume XX - 2017 - Issue 1

The journal is indexed in: PROQUEST / DOAJ / Crossref / EBSCOhost / INDEX COPERNICUS / DRJI / OAJI I

JOURNAL INDEX I I2OR / SCIENCE LIBRARY INDEX / Google Scholar / Academic Keys/ ROAD Open Access I Academic Resources / Scientific Indexing Services / SCIPIO / JIFACTOR

[14] Reese, G., Cloud Application Architectures, O’Reilly

[15] Roya, S.S., Pratiharb, D.K., Soft computing-based expert systems to predict energy consumption and stability margin in turning gaits of six-legged robots, Expert Systems with Applications 39 (2012) 5460-5469

[16] Sahin, S., Tolun, M.R. Hassanpour, R., Hybrid expert systems: A survey of current approaches and applications, Expert Systems with Applications 39 (2012) 4609-4617

[17] Saufi, N.A.A., Daud, S., Hassan, H., 2016, Green Growth and Corporate Sustainability Performance, 7th International Economics \& Business Management Conference, 5th \& 6th October 2015, Procedia Economics and Finance, vol. 35, p. 374-378

[18] Schniederjans, D.G., Hales, D.N., 2016, Cloud Computing and its impact on economic and environmental performance: A transaction cost economic perspective, Decision Support Systems, vol. 86, p. 73-82

[19] Stacchezzini, R., Melloni, G., Lai, A., 2016, Sustainability management and reporting: the role of integrated reporting for communicating corporate sustainability management, Journal of Cleaner Production, p. 1-9

[20] Steiner, T., Khiabani, H., An Introduction To Securing a Cloud Environment,

[21] Sudha, M., "Enhanced Security Framework to Ensure Data Security in Cloud Computing Using Cryptography," Advances in Computer Science and its Applications, vol. 1, no. 1, pp. 32-37, 2012.

[22] Williams, B., 2012, The Economics of Cloud Computing, Cisco

[23]http://www.dell.com

[24] https://www.gartner.com/webinar/3169018?srcld=1-6731481589

[25]http://www.nist.gov/

[26]http://www.tutorialspoint.com//html/index.htm

[27]http://www.tutorialspoint.com//jdbc/jdbc-introduction.htm

[28]http://www.tutorialspoint.com/angularjs/

[29]http://www.tutorialspoint.com/artificial_intelligence/artificial_intelligence_expert_systems.htm

[30]https://aws.amazon.com/security/ 